\title{
Detection and Retrieval of Multi-layered Cloud Properties Using Satellite Data
}

\author{
Patrick Minnis*a, Sunny Sun-Mack ${ }^{\mathrm{b}}$, Yan Chen $^{\mathrm{b}}$, Helen $\mathrm{Yi}^{\mathrm{c}}$, Jianping Huang ${ }^{\mathrm{c}}$ \\ Louis Nguyen, ${ }^{\mathrm{a}}$ Mandana M. Khaiyer ${ }^{\mathrm{c}}$ \\ ${ }^{a}$ Climate Sciences Branch, NASA Langley Research Center, MS 420, Hampton, VA, USA 23681; \\ ${ }^{\mathrm{b}} \mathrm{SAIC}, 1$ Enterprise Parkway, Hampton, VA, USA 23666; \\ ${ }^{c}$ AS\&M, Inc., 1 Enterprise Parkway, Hampton, VA, USA 23666
}

\begin{abstract}
Four techniques for detecting multilayered clouds and retrieving the cloud properties using satellite data are explored to help address the need for better quantification of cloud vertical structure. A new technique was developed using multispectral imager data with secondary imager products (infrared brightness temperature differences, BTD). The other methods examined here use atmospheric sounding data $\left(\mathrm{CO}_{2}\right.$-slicing, $\left.\mathrm{CO} 2\right), \mathrm{BTD}$, or microwave data. The $\mathrm{CO} 2$ and BTD methods are limited to optically thin cirrus over low clouds, while the MWR methods are limited to ocean areas only. This paper explores the use of the BTD and $\mathrm{CO} 2$ methods as applied to Moderate Resolution Imaging Spectroradiometer (MODIS) and Advanced Microwave Scanning Radiometer EOS (AMSR-E) data taken from the Aqua satellite over ocean surfaces. Cloud properties derived from MODIS data for the Clouds and the Earth's Radiant Energy System (CERES) Project are used to classify cloud phase and optical properties. The preliminary results focus on a MODIS image taken off the Uruguayan coast. The combined MW visible infrared (MVI) method is assumed to be the reference for detecting multilayered ice-over-water clouds. The BTD and CO2 techniques accurately match the MVI classifications in only 51 and $41 \%$ of the cases, respectively. Much additional study is need to determine the uncertainties in the MVI method and to analyze many more overlapped cloud scenes.
\end{abstract}

Keywords: clouds, cloud overlap, microwave, MODIS, multilayer clouds, AMSR-E, CERES

\section{INTRODUCTION}

Improved characterization of the vertical structure of clouds is needed for the development of better cloud parameterizations and the validation of cloud fields in climate models. Satellite data constitute the most important source for quantitatively describing the distribution of clouds at large and small scales over extended areas. Traditionally, analyses of satellite data have been limited to interpreting the radiances in terms of single-layer clouds resulting in large errors in the retrieved properties for multilayered cloud systems. Recently, a variety of methods have been developed to detect multilayered clouds and to estimate the properties of those clouds classified as multi-layered. Combining visible (VIS; $0.65 \mu \mathrm{m}$ ) and infrared (IR) retrievals of cloud properties with microwave (MW) retrievals of cloud water temperature $T w$ and liquid water path $L W P$ appears to be a fruitful approach for detecting and retrieving overlapped clouds ${ }^{1,2,3}$. A method using 1.6- $\mu \mathrm{m}$ reflectance and $11-\mu \mathrm{m}$ brightness temperatures, $T$, shows some potential for unscrambling the cloud impacts on observed radiances ${ }^{4}$, but it has not been extensively used. The use of BTD, the 11-12 $\mu \mathrm{m}$ brightness temperature difference, in conjunction with $\tau$, the retrieved visible optical depth, was suggested ${ }^{5}$ as a means to detect multilayered clouds. A slightly different approach was developed using the BTD along with the VIS reflectance $^{6}$ and has been applied to detect multilayered clouds using daytime data taken over most non-polar regions ${ }^{7}$. The discrepancy between cloud-top pressure derived from a $\mathrm{CO}_{2}$-slicing retrieval and the IR-based cloud pressure has been exploited to detect overlapped clouds and retrieve the properties of each layer ${ }^{8}$ over a large portion of the Earth ${ }^{9}$. These recent ventures into passive remote sensing of multilayered clouds are encouraging, but the accuracy of these retrievals and their limitations, especially regarding detectability, are poorly understood. To begin characterizing which clouds are detected and retrieved properly, this paper performs some initial comparisons of these techniques and another method recently developed for application to both geostationary and polar-orbiting satellite imagery.

*p.minnis@nasa.gov; phone 1757 864-5671; fax 1757 864-7996; www-pm.larc.nasa.gov 


\section{DATA}

Data from the Moderate Resolution Imaging Spectroradiometer (MODIS) and the Advanced Scanning Microwave Radiometer-EOS (AMSR-E) on the Aqua satellite are used to perform the various retrievals. The 1-km MODIS data are analyzed for the Clouds and the Earth's Radiant Energy System ${ }^{10}$ (CERES) using the VIS-IR-Solar-infrared-Splitwindow Technique ${ }^{11}$ (VISST) to retrieve single-layer (SL) cloud properties for each pixel ${ }^{12}$. The CERES cloud retrieval output, which includes the cloud properties such as cloud optical depth $\tau$ and cloud effective temperature $T c$, as well as the original pixel radiances at $0.64,1.6,2.1,3.7,11$, and $12 \mu \mathrm{m}$, for each pixel is combined with the radiances for the 1.3, 4.0, 6.7, 8.5, 13.3, 13.5, 13.9, and 14.2- $\mu \mathrm{m}$ MODIS channels. Cloud $L W P$ and $T w$ are derived from the AMSR-E MW data at the 12-km resolution $36.5-\mathrm{GHz}$ field of view (FOV) by matching the multispectral MW data to radiative transfer model (RTM) calculations ${ }^{13}$. The CERES pixel-level results are then convolved into the AMSR-E footprints following an earlier approach ${ }^{2}$ in order to apply the MW-VIS-IR (MVI) multilayered cloud detection method ${ }^{1}$ and retrieve cloud properties using the VIS two-layer cloud retrieval technique ${ }^{3}$ VTRT. In this pilot study, the CERES MODIS pixels are matched to the nominal nadir-size footprint of the AMSR-E to facilitate comparison of the different techniques.

The comparative analyses focus on one granule of Aqua MODIS data taken 13 July 2004 off the coast of Uruguay at 1316 UTC. The RGB MODIS image in Figure 1 shows a complex system with a mixture of ice (pinkish, grayish). liquid water (white, yellow, and peach), and overlapped clouds. Also shown are the VISS-retrieved values of $\tau$ for all cloud types assuming SL clouds. The cloud optical depths range from 0.3 up to 128.

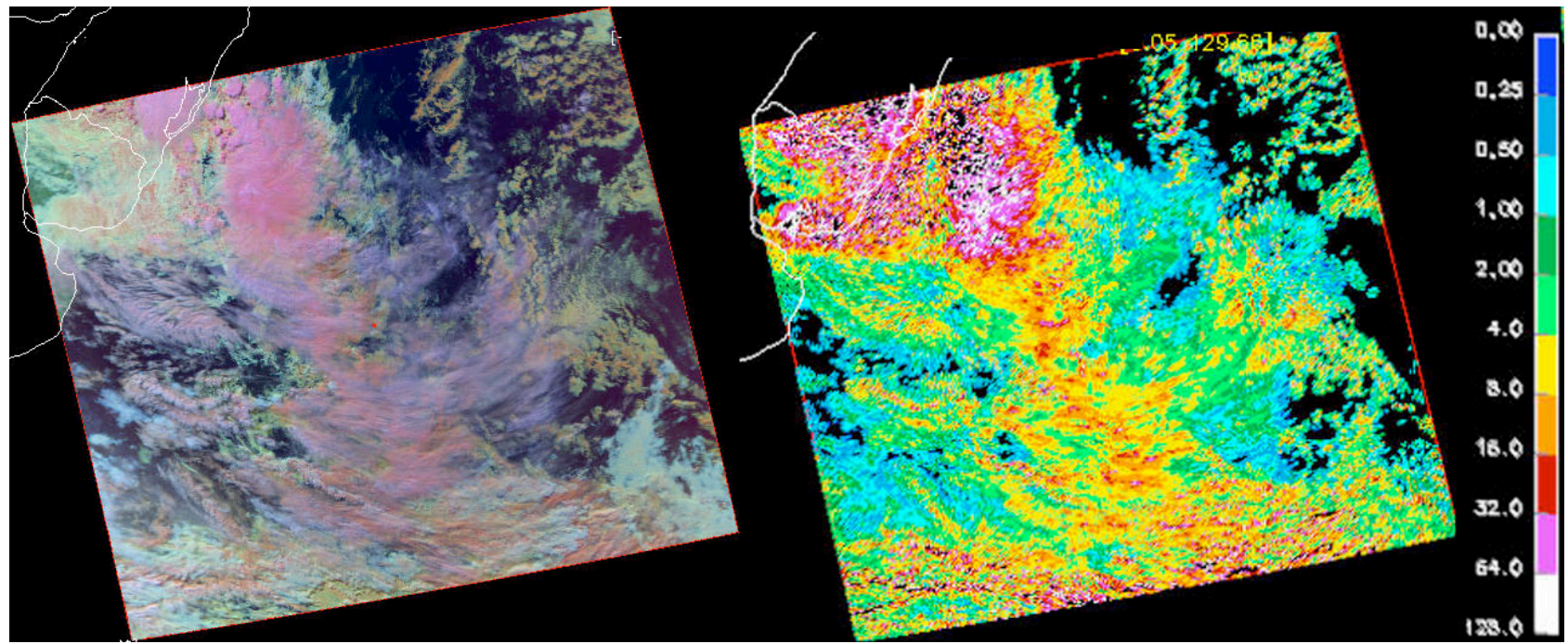

Figure 1: CERES imagery for multilayer cloud detection comparisons for 1316 UTC, 13 July 2004. left: Aqua MODIS pseudo-color RGB image. right: VISST-derived cloud optical depth.

\section{METHODOLOGIES}

Four different ML cloud techniques are compared here; the MVI, the VIS BTD method ${ }^{6}$ (VBM), the $\mathrm{CO}_{2}$-slicing $\operatorname{method}^{8}(\mathrm{COM})$, and the CERES BTD method (CBM). The MVI is used as the reference technique because it can detect water clouds over ocean in the presence of ice clouds as long as no precipitation occurs. While it is not possible to exactly duplicate the published techniques, every effort is made here to match them as closely as possible.

\subsection{MVI}

The MVI is used only if the VISST retrieves at least $98 \%$ ice cloud coverage for the MODIS pixels in the convolved AMSR field of view and the solar zenith angle is less than $78^{\circ}$. The scene is classified as being composed of SL ice clouds, if the retrieved MW $L W P \leq 40 \mathrm{gm}^{-2}$. If $L W P>40 \mathrm{gm}^{-2}, T w-T c>5 \mathrm{~K}$, and no precipitation is detected, the scene is classified as ML ice clouds, that is, an ice over a water cloud system. The precipitation detection is based on the 
amount of polarization in the $36.5-\mathrm{GHz}$ channel. Single-layer water, clear, partly cloudy, and mixed phase scenes are not considered here.

\subsection{VBM}

The VBM has two formulations, one for an imager with only a few channels and one with many spectral channels like the MODIS ${ }^{6}$. The multispectral approach, approximated here, uses $B T D$, the VIS reflectance $R_{v}, T$, and the 1.3 and 1.6$\mu \mathrm{m}$ reflectances, $R_{i}$ and $R_{n}$, respectively. The pixel is first assumed to be SL. It is reclassified as ML if either one of the following tests are satisfied over ocean, snow, or ice surfaces.

$$
\begin{aligned}
& \text { 3.2.I) } 0.3<R_{v}<1.0 \text { and BTD }>T H b \text { and } T<270 \mathrm{~K} \text {. } \\
& \text { 3.2.II) } 0.025<R_{i}<0.4 \text { and } \mathrm{R}_{\mathrm{n}}>T H n \text { and } T<280 \mathrm{~K} \text { and } R_{n} / R_{v}<1.0 \text { and }\left(B T D<T H b \text {, if } R_{i}<0.08\right) \text {. }
\end{aligned}
$$

Values for the BTD and near-infrared thresholds, $T H b$ and $T H n$, respectively, are available in lookup tables ${ }^{6}$. $T H b$ depends on surface type, $R_{v}$ and the viewing and solar zenith angles, while $T H n$ varies as a polynomial function of $R_{i}$. The Aqua MODIS $1.6-\mu \mathrm{m}$ channel has not functioned properly and is essentially useless. Since it is similar in reflectance behavior over ocean and clouds, the 2.1- $\mu \mathrm{m}$ channel is used here instead of $1.6 \mu \mathrm{m}$. To account for the differences, the 1.6 and 2.1- $\mu \mathrm{m}$ channels on the Terra MODIS were compared over clouds to derive a near-infrared threshold THn(2.1) in VBM test 3.2.II. This initial threshold value is

$$
\operatorname{THn}(2.1)=0.58 \operatorname{THn}(1.6)
$$

The validity of this threshold formula can only be determined by further application of the VBM to Terra MODIS data using the 1.6 and $2.1-\mu \mathrm{m}$ channels separately for the same pixels.

\subsection{COM}

The COM method is applied in the following manner with the initial assumption that the pixel contains only SL clouds. The following tests are applied to pixels having a valid VISST retrieval as a an ice or water cloud. For water clouds, the pixel contains multilayered cloud if

$$
\text { 3.3.I) } \quad \varepsilon(\mathrm{V})-\varepsilon(\mathrm{C})>0.3 \text { and } z(\mathrm{C})-z(\mathrm{~V})>1.5 \mathrm{~km} \text { and } \varepsilon(\mathrm{V})>0.9 \text { and } r_{e}>9 \mu \mathrm{m} \text { and } p(\mathrm{C})<450 \mathrm{hPa} \text {, }
$$

In this test, $\varepsilon, z$, and $p$ denote the cloud emissivity, height, and pressure, respectively, as computed from the VISST (V) or the CO2-slicing (C) methods. The VISST-derived effective droplet radius is $r_{e}$.

For ice clouds, the optical depth limit is computed as

$$
\mathrm{ODL}=0.96-1.09[\mu \ln [1-\varepsilon(\mathrm{C})]
$$

where the cosine of the viewing zenith angle is $\mu$. The cloud is classified as ML ice is the following test is satisfied.

$$
\text { 3.3.II) } \quad p(\mathrm{C})<500 \mathrm{hPa} \text { and } \tau(\mathrm{V})>\mathrm{ODL} \text { and } \varepsilon(\mathrm{C})<0.85 \text {. }
$$

An additional set of tests is applied if the cloud is ice and $\tau(\mathrm{V})>20$. The cloud layering is classified as indeterminate if any one of the following statements is true.

$$
\begin{aligned}
& \text { 3.3.IIIa) }-0.5 \mathrm{~K}<\mathrm{BTD}<0.5 \mathrm{~K} . \\
& \text { 3.3.IIIb) } 3.0 \mathrm{~K}<T-T(3.7 \mu \mathrm{m})<3.0 \mathrm{~K} . \\
& \text { 3.3.IIIc) }-3.0 \mathrm{~K}<T-T(4.0 \mu \mathrm{m})<3.0 \mathrm{~K} . \\
& \text { 3.3.IIId) }-3.0 \mathrm{~K}<T-T(6.7 \mu \mathrm{m})<3.0 \mathrm{~K} . \\
& \text { 3.3.IIIe) }-0.5 \mathrm{~K}<T-T(8.5 \mu \mathrm{m})<0.5 \mathrm{~K} \text {. } \\
& \text { 3.3.IIIf) }-3.0 \mathrm{~K}<T-T(13.3 \mu \mathrm{m})<3.0 \mathrm{~K} \text {. }
\end{aligned}
$$


The values of the brightness temperatures $T(\lambda)$ correspond to observed value for the given channel wavelength, $\lambda$. The tests in 3.3.III are designed to account for the uncertainty in the height of the lower cloud and are not part of the original $\mathrm{COM}^{9}$. Whenever a thin high cloud occurs above a thick ice cloud, it can produce brightness temperature differences approximately within the ranges given in 3.3.III limits. The indeterminate category basically assumes that the ice cloud is too thick to reliably determine whether a water cloud resides underneath the ice cloud. This type of condition often arises for convective clouds.

The COM serves as a starting point for a retrieval process that first searches for the average properties of nearby low clouds. They serve as the initial properties of the lower cloud, indicated by the subscript $l$, for use in RTM calculations of the VIS reflectance at the satellite view. The cloud input for the RTM consists of $\tau_{1}, r_{e l}$, and $T_{l}$ from the neighboring pixels for the lower cloud and $\tau_{u}, D_{e \mathrm{u}}$, and $T_{u}$ from the $\mathrm{CO}_{2}$-slicing and VISST retrieval for the upper cloud. The $\mathrm{CO}_{2}-$ slicing retrieval and lower cloud properties are iterated with adjustment of the appropriate parameters before each new step until the calcualted VIS reflectance matches $R_{v}$. The output includes cloud properties for each layer.

\subsection{CBM}

The CBM is a technique, newly formulated following the suggestion of earlier research ${ }^{5}$, that uses the VISST-derived parameters and the BTD to classify cloudy pixels as SL, ML, or indeterminate. Figure 2 shows the flow diagram for the CBM. It begins with the VISST retrieval and applies different tests depending on the phase of the SL retrieval. In addition to $\tau$, the CBM uses either the effective ice crystal diameter $D_{e}$ or $r_{e}$ depending on the phase. In addition to the tests listed in the flowchart, the CBM applies the same indeterminate tests (3.3.III) as the COM for all ice clouds with $\tau$ $>20$. For clouds classified as ML, the upper and lower cloud properties are estimated in manner similar to the COM, except that the Solar-infrared Infrared Split-window Technique ${ }^{11}$ (SIST) is used to estimate $\tau_{u}$ because no $\mathrm{CO}_{2}$ bands are used. To improve the height determination, the SIST is also used for SL clouds when the VISST retrieves $\tau<4$. No iteration is performed in this prototype version.

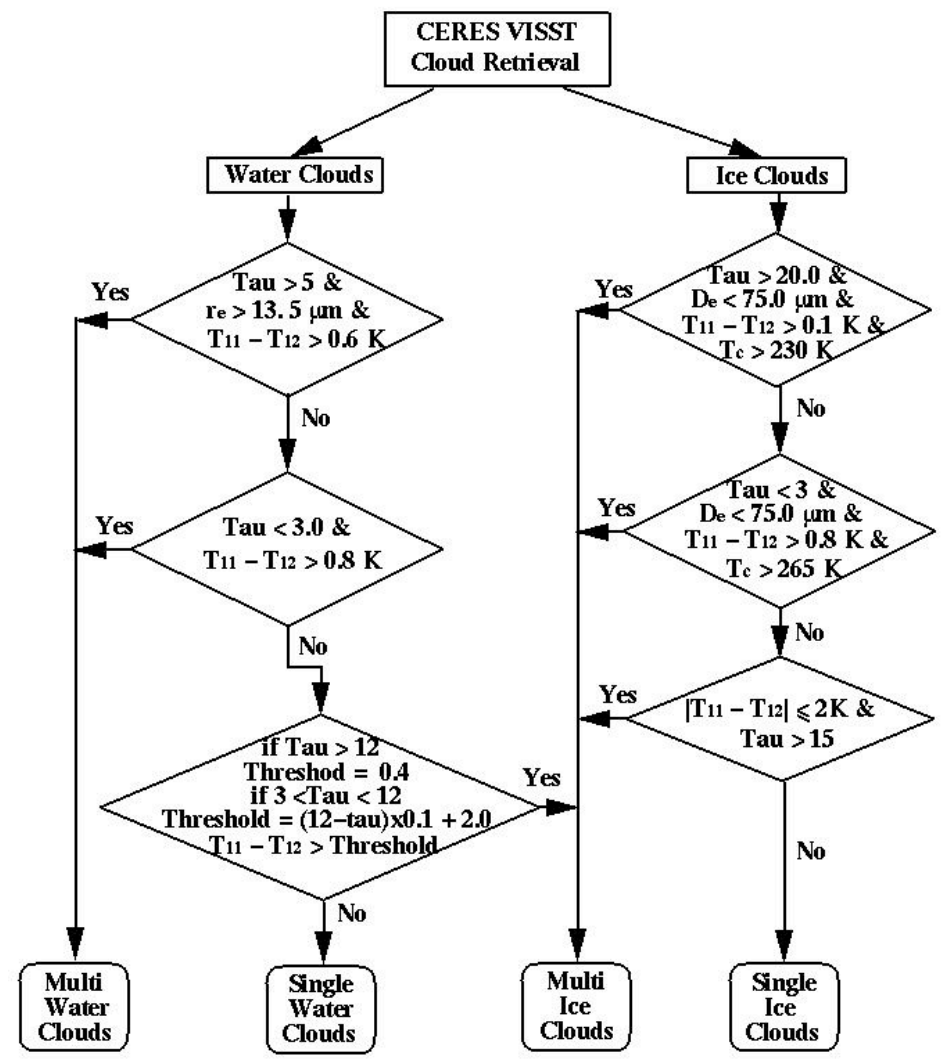

Figure 2: Flow chart for classifying VISST retrievals as single or multi-layered clouds in the CERES BTD Method. 
a) Cloud Physics Lidar, ER2 / CRYSTALFACE, July 26, 2002
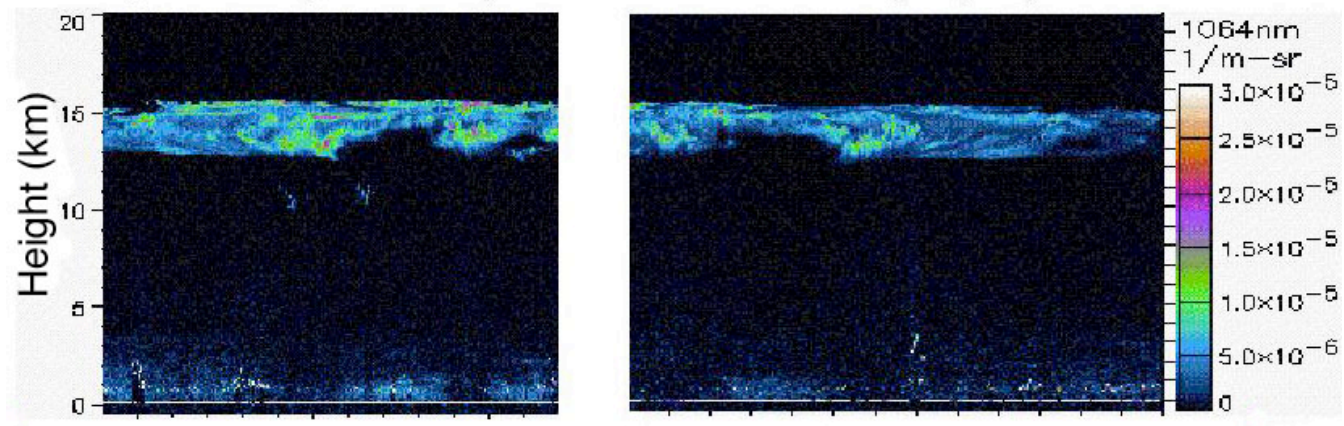

b) Observed Aqua MODIS BTD

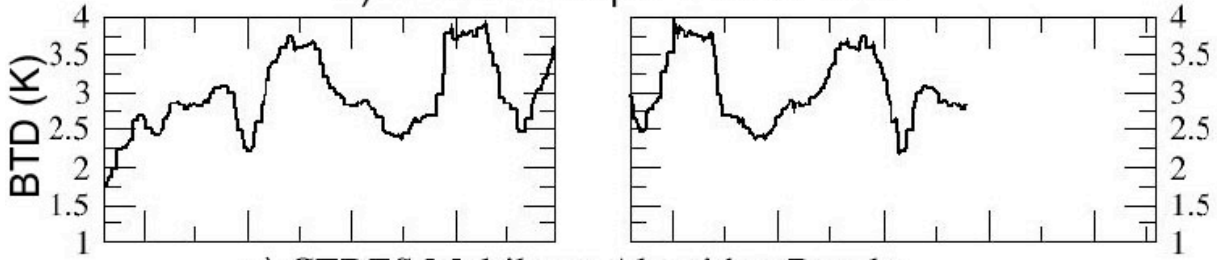

c) CERES Multilayer Algorithm Results
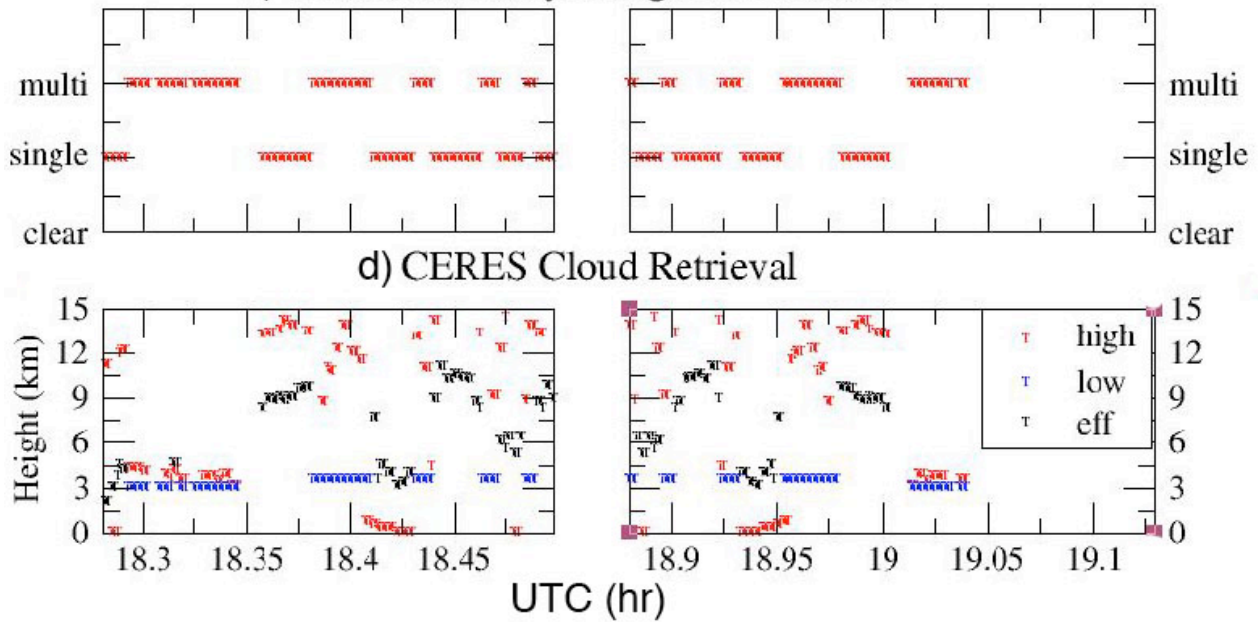

Figure 4: Multilayered cloud case over the Gulf of Mexico with matched MODIS and ER-2 CPL data, 1830 UTC, 26 July 2002.

An example of the CBM applied to Aqua MODIS data is shown in Figure 3 for a match with the Cloud Physics Lidar ${ }^{14}$ (CPL) on the ER-2 as it flew over the Gulf of Mexico during 26 July 2002. The CPL detects a thin cirrus layer (Figure $3 a)$ between 13 and $15 \mathrm{~km}$ above scattered cumulus clouds between 0.5 and $2 \mathrm{~km}$. The BTD (Figure $3 \mathrm{~b}$ ) along the flight path varies between 2 and $4 \mathrm{~K}$ with larger values coinciding with slightly thicker cirrus and the absence of cumulus clouds. The CBM classification (Figure 3c) detects ML clouds only when the lower cloud appears to be thick (bright) in the CPL return. Although some ML clouds are misclassified as SL, most of the SL clouds are accurately designated. The retrieval method yields mixed results for cloud heights (Figure 3d). At 18.3 UTC, it only produces a slight separation between the high (red) and low (blue) cloud, possibly because the low cloud height was incorrectly specified as being too high. At 18.37 UTC, the clouds are correctly classified as SL and the VISST (black) places the cloud between 9 and $10 \mathrm{~km}$. The effective cloud height from VISST should be located somewhere between the cloud base and top. The SIST yields a more accurate retrieval of Z, placing the cloud between 13 and $14 \mathrm{~km}$. At $18.40 \mathrm{UTC}$, the clouds are categorized as ML. The VISST retrieval is basically the same as the low cloud (blue), while the high cloud retrieval is between 9 and $14 \mathrm{~km}$, certainly an improvement over the VISST retrieval. At 18.42 UTC, the ML cloudiness is misclassified as SL because the lower cloud is optically thin. In this case, the VISST retrieval is more accurate than the SIST. Results for the remainder of track are similar to those from the first part of the flight. This prototype retrieval is promising, but the iterations and conditions for application need to be implemented to fully assess its capabilities. 


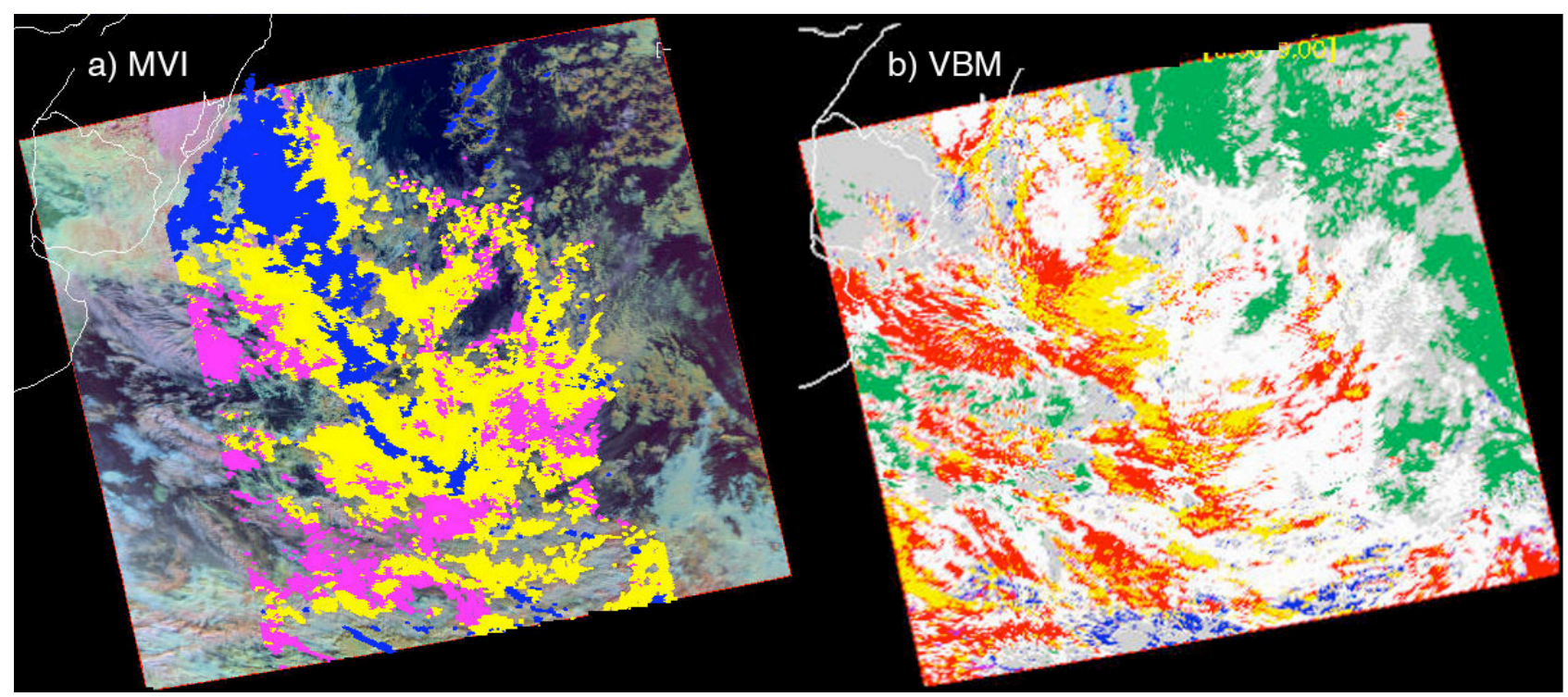

Figure 4: Cloud layering classifications for scene in Figure 1. (a) MVI: blue - precipitation, yellow - ML ice, magenta - SL ice. (b) VBM: white - SL ice, gray - SL water, yellow- ML ice from 2.2.I, red - ML ice from 3.2.II, dark blue - ML water from 3.2.I, light blue - ML water from 3.2.II, green - clear.

\section{RESULTS AND DISCUSSION}

The four ML detection methods were applied to the scene in Figure 1 and are compared below. Figure 4 shows the classifications from the MVI (Figure 4a) and the VBM (Figure 4b). The MVI is restricted to the center of the swath because the AMSR-E scans conically at a viewing zenith angle of $55^{\circ}$. Thus, all comparisons with the MVI use only those MODIS pixels over water taken at a viewing zenith angle of $55^{\circ}$ or less. Results from the COM and CBM are shown in Figures 5a and 5b, respectively. The MVI precipitating clouds correspond to indeterminate, ML, and SL ice clouds from the other methods as well as to some SL water clouds. The MVI ML clouds typically correspond to different ML clouds from the various other techniques. The CBM and VBM are most similar, at least, in the yellow areas, however, the VM 3.2.II test (red) classifies more pixels as ML. Some correspond to MVI ML pixels, while others coincide with MVI SL pixels.

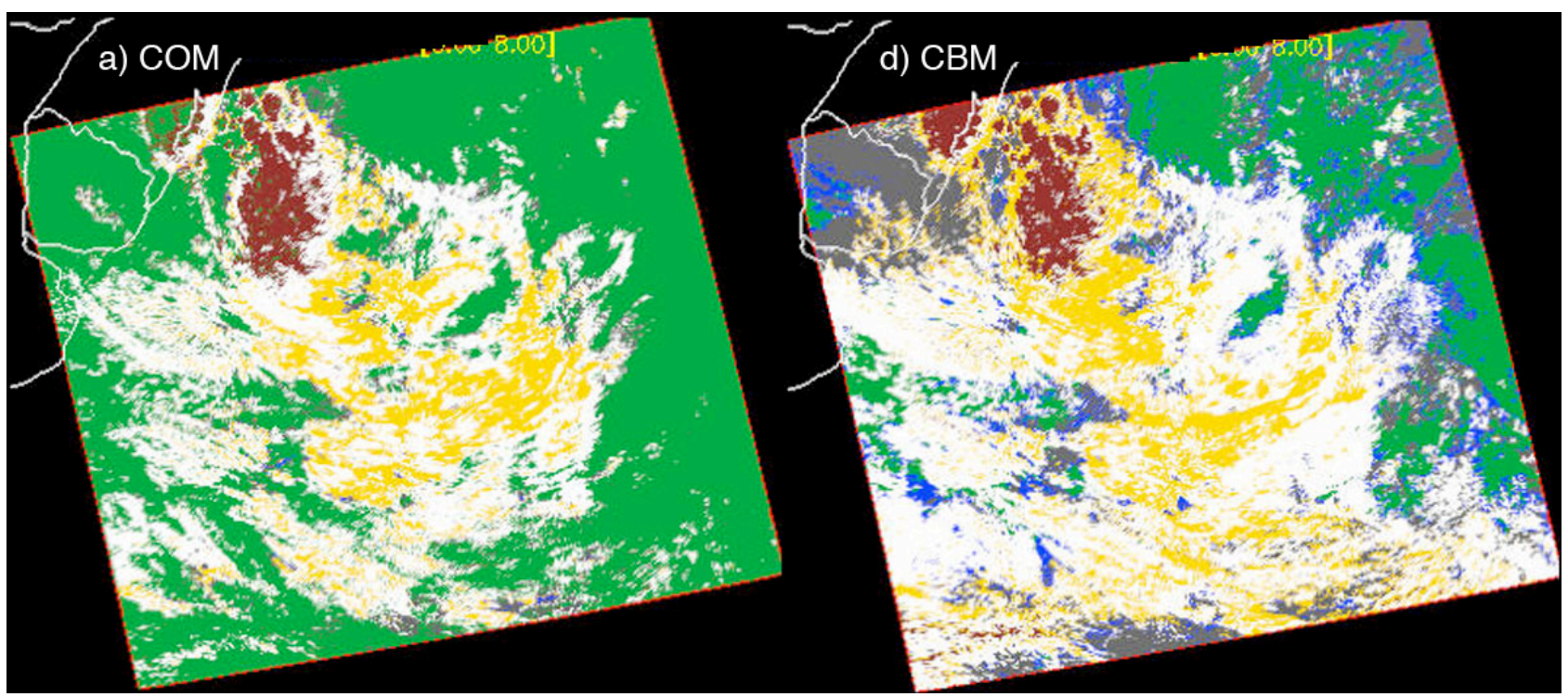

Figure 5: Cloud layering classifications for scene in Figure 1. (a) COM: brown - indeterminate, yellow - ML ice, white - SL ice. (b) CBM: brown - indeterminate, white - SL ice, gray - SL water, yellow- ML ice, dark blue - ML water, green - clear. 
Table 1. BDM classification of MODIS pixels in marine AMSR-E pixels containing $100 \%$ cloud cover as determined by the VISST for the same MODIS pixels. Results in \% of total number of MODIS pixels, except N(AMSR).

\begin{tabular}{cccccccc}
\hline MVI class & SL water & SL Ice & ML water & ML ice & indeterminate & clear & N(AMSR) \\
\hline ML ice & 0.4 & 27.2 & 0.1 & 29.3 & n/a & 0.0 & 11632 \\
SL ice & 0.1 & 9.9 & 0.0 & 11.2 & n/a & 0.1 & 4429 \\
precipitation & 2.4 & 9.6 & 0.6 & 8.8 & n/a & 0.1 & 4260 \\
\hline
\end{tabular}

Table 2. Same as Table 1, except for the COM results.

\begin{tabular}{cccccccc}
\hline MVI class & SL water & SL Ice & ML water & ML ice & indeterminate & $\begin{array}{c}\text { no high } \\
\text { cloud }\end{array}$ & N(AMSR) \\
\hline ML ice & 0.2 & 28.2 & 0.0 & 18.7 & 2.4 & 7.5 & 11632 \\
SL ice & 0.1 & 13.0 & 0.0 & 6.0 & 0.1 & 2.2 & 4429 \\
precipitation & 0.5 & 5.8 & 0.0 & 3.1 & 7.1 & 5.0 & 4260 \\
\hline
\end{tabular}

Table 3. Same as Table 1, except for CBM results.

\begin{tabular}{cccccccc}
\hline MVI class & SL water & SL Ice & ML water & ML ice & indeterminate & clear & N(AMSR) \\
\hline ML ice & 0.3 & 30.3 & 0.2 & 24.2 & 2.0 & 0.0 & 11632 \\
SL ice & 0.1 & 15.0 & 0.1 & 5.9 & 0.2 & 0.1 & 4429 \\
precipitation & 2.7 & 4.7 & 0.3 & 6.7 & 7.0 & 0.1 & 4260 \\
\hline
\end{tabular}

The comparisons with the MVI results are quantified in Tables 1-3. The numbers represent the percent of all MODIS pixels within the FOVs of all AMSR-E pixels having an MVI classification. Because the MVI is only used for AMSR-E pixels having at least $98 \%$ ice cloud coverage from the VISST or are precipitating, the percentages will exclude most clear and SL and ML water pixels from consideration. The VBM (Table 1) yields the closest match for ML ice at 29.3\%. It is followed by the CBM (Table 3) and then the COM (Table 2). The latter finds no high clouds in 13\% of the MVI ML cases. The number of indeterminate pixels is similar for both the COM and CBM because nearly identical methods are used for that category. The CBM yields the best agreement with the MVI for SL ice at $15 \%$ followed by the COM and VBM, respectively. The retrievals for MVI precipitating clouds (PRCP) vary considerably for each of methods. The CBM and VBM classify roughly $12 \%$ of the PRCP as SL water clouds because both rely on the VISST to determine phase. The indeterminate category is assigned to $33 \%$ of the PRCP pixels by both the COM and CBM . Because it has no indeterminate class, the VBM assigns about $30 \%$ of the indeterminate pixels to ML ice and the remainder to SL ice.

An overall score for these techniques relative to the MVI retrievals can be assessed by considering only the nonprecipitating AMSR-E pixels. A correct classification is assumed if the technique yields ML clouds when the MVI detects ML ice and SL clouds when the MVI retrieves SL water. Given that basis, the VBM, COM, and CBM yield accurate classifications in 50.3, 40.5, and $50.6 \%$ of the cases. The accuracies for the VBM and CBM are nearly the same despite the differences in ML classifications. Accepting the assumption that the MVI is accurate, these results suggest that the three other ML detection methods are not demonstrating the kind of skill required for reliable detection of ML clouds. Some of the errors in the ML methods may be due to inaccuracies in matching the MODIS pixels used in the MODIS-only retrievals because the nadir FOV size was assumed for the matching. However, a comparison of the images in Figures 4 and 5 indicate that this not likely to explain more than a few percent of the differences in classifications. Another source of error is the assumption that in an AMSR-E FOV, the entire area is covered by a water cloud when $L W P>40 \mathrm{gm}^{-2}$ and by no water when $L W P<40 \mathrm{gm}^{-2}$. This is a reasonable assumption given that the detectability of $L W P$ from MW data is highly uncertain when the $L W P$ is below that limit and it corresponds to a lower cloud optical depth of $\sim 5$ for $r_{e}=12 \mu \mathrm{m}$. Detection of ML clouds with the MODIS data alone is likely to be difficult if $\tau_{\mathrm{u}}<5$. However, if the clouds under the are scattered and have optical depths exceeding 5 , then the MVI might classify 
the cloud as SL ice while the MODIS methods could classify a third or more of the pixels as ML and be correct. Conversely, the AMSR-E pixel could be half covered by optically thick cumulus clouds and be classified as ML ice while only half of the MODIS pixels are categorized as ML and be correct. The limitations of using the MVI clearly need further examination.

\section{CONCLUDING REMARKS}

Preliminary comparisons of four different multi-layered cloud detection methods confirm that passive remote sensing of multilayered cloud systems is a difficult and possibly intractable approach for a variety of cloud systems. No pessimistic conclusions should be drawn from the results, however, because only one scene was analyzed, the various techniques have not been optimized, and the uncertainties and limitations of the reference MVI method have not been clearly defined. A framework for performing more detailed and robust comparisons has been established, thus, facilitating the analysis of multilayered clouds over the global oceans and for incorporating the optimized algorithms for both published and unpublished detection methods. By further detailed examination of the MVI in conjunction with surface, airborne, and satellite lidar-radar systems, it should be possible to determine the uncertainties in a given retrieval. The capabilities of the other methods can then be assessed using both the active sensors and the MVI to cover more cloud types and viewing angles than would be possible using the active sensors alone.

\section{ACKNOWLEDGMENTS}

This research is supported by the NASA Science Mission through the CERES and CRYSTAL-FACE programs. The ER-2 image was obtained from the CPL home page, http://cpl.gsfc.nasa.gov/.

\section{REFERENCES}

1. Lin, B., P. Minnis, B. A. Wielicki, D. R. Doelling, R. Palikonda, D. F. Young, and T. Uttal, Estimation of water cloud properties from satellite microwave and optical measurements in oceanic environments. II: Results. $J$. Geophys. Res., 103, 3887-3905, 1998.

2. Ho, S.-P., B. Lin, P. Minnis, and T.-F. Fan, Estimation of cloud vertical structure and water amount over tropical oceans using VIRS and TMI data. J. Geophys. Res., 108 (D14), 4419, 10.1029/2002JD003298, 2003.

3. Huang, J., P. Minnis, B. Lin, Y. Yi, M. M. Khaiyer, R. F. Arduini, and G. G. Mace, Advanced retrievals of multilayered cloud properties using multi-sensor and multi-spectral measurements. J. Geophys. Res., 110, 10.1029/2004JD005101, 2005.

4. Baum, B. A., and J. D. Spinhirne, Remote sensing of cloud properties using MODIS airborne simulator imagery during SUCCESS, 3. Cloud overlap. J. Geophys. Res., 105, 11,793-11,804, 2000.

5. Kawamoto, K., P. Minnis, and W. L. Smith, Jr., Cloud overlapping detection algorithm using solar and ir wavelengths with GOES data over ARM/SGP site. Proc. 11th ARM Science Team Meeting, March 18-22, Atlanta, GA, 2001. Available at http://www.arm.gov/docs/documents/technical/conf_0103/author.html.

6. Pavlonis, M. J. and A. K. Heidinger, Daytime cloud overlap detection using AVHRR and VIIRS. J. Appl. Meteorol., 43, 762-778, 2004.

7. Heidinger, A. K. and M. J. Pavlovis, Global daytime distribution of overlapping cirrus cloud from NOAA's Advanced Very High Resolution Radiometer. J. Climate, in press, 2005.

8. Chang, F.-L. and Z. Li, A new method for detection of cirrus-overlapping-water clouds and determination of their optical properties. J. Atmos. Sci., in press, 2005.

9. Chang, F.-L. and Z. Li, A near-global climatology of single-layer and overlapped clouds and their optical properties from Terra/MODIS data using a new algorithm. J. Climate, in press, 2005.

10. Wielicki, B. A., B. R. Barkstrom, E. F. Harrison, R. B. Lee, III, G. L. Smith, and J. E. Cooper, Clouds and the Earth's Radiant Energy System (CERES): An Earth Observing System Experiment, Bull. Am. Meteorol. Soc., 77, 853-868, 1996.

11. Minnis, P., D. P. Kratz, J. A. Coakley, Jr., M. D. King, D. Garber, P. Heck, S. Mayor, D. F. Young, and R. Arduini, Cloud Optical Property Retrieval (Subsystem 4.3). "Clouds and the Earth's Radiant Energy System (CERES) Algorithm Theoretical Basis Document, Volume III: Cloud Analyses and Radiance Inversions (Subsystem 4)", NASA RP 1376 Vol. 3, edited by CERES Science Team, pp. 135-176, 1995. 
12. Minnis, P., D. F. Young, B. A. Wielicki, S. Sun-Mack, Q. Z. Trepte, Y. Chen, P. W. Heck, and X. Dong, A global cloud database from VIRS and MODIS for CERES. Proc. SPIE $3^{\text {rd }}$ Intl. Asia-Pacific Environ. Remote Sensing Symp. 2002: Remote Sens. of Atmosphere, Ocean, Environment, and Space, Hangzhou, China, October 23-27, Vol. 4891, 115-126, 2002.

13. Lin, B., B. A. Wielicki, P. Minnis, and W. B. Rossow, Estimation of water cloud properties from satellite microwave and optical measurements in oceanic environments. I: Microwave brightness temperature simulations. J. Geophys. Res., 103, 3873-3886, 1998.

14. McGill, M. J., L. Li, W. D. Hart, G. M. Heymsfield, D. L. Hlavka, P. E. Racette, L. Tian, M. A. Vaughan, and D. M. Winker, "Combined lidar-radar remote sensing: Initial results from CRYSTAL-FACE", J. Geophys. Res., 109, doi: 10.1029/2003JD004030, 2004. 